\title{
Penerapan sistem pendidikan disentralisasi serta upaya peningkatan mutu layanan dengan pengembangan profesionalisme guru bimbingan konseling
}

\author{
Berru Amalianita $^{1^{*}}$, Firman Firman ${ }^{2}$, Riska Ahmad ${ }^{3}$ \\ ${ }^{123}$ Universitas Negeri Padang
}

\begin{tabular}{l} 
Article Info \\
\hline Article history: \\
Received Jan $12^{\text {th }}, 2021$ \\
Revised Jan $30^{\text {th }}, 2021$ \\
Accepted Feb $08^{\text {th }}, 2021$ \\
\hline
\end{tabular}

\section{Keyword:}

Desentralisasi Pendidikan Profesionalisme

Guru BK

\begin{abstract}
ABSTRAK
Dengan pendekatan desentralisasi ini maka ruang gerak guru BK menjadi leluasa. Proses kreatif dan inovatif justru menjadi lebih utama. guru BK didorong untuk memiliki keberanian dan membiasakan diri untuk menemukan cara-cara baru yang lebih efektif dan efisien dalam melaksanakan berbagai kegiatan pelayanan bimbingan dan konseling yang ditutut bekerja secara profesional. Peningkatan mutu serta kulitas pelayanan bimbingan dan konseling di dukung dengan profesonalitas guru BK sebagai pemberi layanan. Pembentukan keprofesionalan guru BK dapat ditingkatkan melalui pengembangan profesionalisme dari guru BK. Artinya guru BK dapat memiliki sikap atau cara kerja yang mengutamakan keprofesionalan dalam bekerja, selalu ingin mengembangkan profesinya, memiliki rasa banggakan akan profesi serta selalu berusaha meningkatkan kemampuan serta keterampilan untuk dapat mewujudkan mutu pelayanan bimbingan dan konseling yang baik.
\end{abstract}

(C) 2021 The Authors. Published by IICET

This is an open access article under the CC BY-NC-SA license

(https://creativecommons.org/licenses/by-nc-sa/4.0)

\section{Corresponding Author:}

Berru Amalianita,

Universitas Negeri Padang

Email: Berruamalianita10@gmail.com

\section{Pendahuluan}

Sistem pendidikan nasional telah disempurnakan dan disesuaikan dengan perkembangan kemajuan ilmu pengetahuan dan teknologi serta kondisi sosial budaya, di dalamnya sarat dengan prinsip-prinsip pendidikan yang berlandaskan kesatuan dan keutuhan nasional, menjunjung tinggi kepribadian bangsa yang bermartabat dan bermoral, kreativitas, keterampilan dan sebagainya (Achmad \& Ashariana, 2021; Kuswandi, 2011). Pendidikan di Indonesia terus mengalami perubahan dari pola manajemen sentralisitik birokratik menuju desentralisitik profesional. Di Indonesia, upaya implementasi desentralisasi pendidikan mendapat landasan kuat ketika UU No 22 tahun 1999 mengenai otonomi daerah disahkan. Undang-undang mengenai otonomi daerah ini membawa implikasi yang sangat luas, termasuk di dalamnya perubahan paradigma manajemen pendidikan dari yang sentralistik ke arah desentralistik (Pasandaran, 2016; Siburian, 2020). Dalam konteks pelaksanaan otonomi daerah ditegaskan bahwa sistem pendidikan nasional yang bersifat sentralistis selama ini kurang mendorong terjadinya demokratisasi dan desentralisasi penyelenggaraan pendidikan. Sebab sistem pendidikan yang sentralisasi diakui kurang bisa mengakomodasi keberagaman daerah, keberagaman sekoah, serta keberagaman peserta didik, bahkan cendrung mematikan partisipasi masyarakat dalam pengembangan pendidikan (Achmad \& Ashariana, 2021; Waji, 2015). 
Desentralisasi pendidikan memberikan kewenangan secara penuh terhadap pemerintah daerah untuk merencanakan, melaksanakan, dan menentukan dengan peraturan dan perundan-undangan yang berlaku di daerah (Gaol, 2020; Kuswandi, 2011). Demokrasi pendidikan memberikan kewenang-an secara penuh atas partisipasi masyarakat secara luas dalam menyelenggarakan pendidikan dengan ikut menentukan arah dan kebijakan merumuskan strategi, sasaran, tujuan pendidikan, serta terlebih aktif dalam implementasinya (Amelia, Firman, \& Rusdinal, 2019; Yuhasnil, 2020). Pada pendekatan sentralistik konselor bekerja disesuaikan dengan kentutuan dan pola yang telah dirancang oleh pusat melaui berbagai bentuk aturan, ketentuan, petunjuk pelaksanaan, petunjuk teknis dan sebagainya yang dapat menghambat dan membatasi ruang gerak guru $\mathrm{BK} /$ konselor sehingga pada akhirnya guru BK menjadi kurang terbiasa dengan budaya kreatif dan inovatif (Kiswantoro, 2014; Rahmadi, 2020).

Kemudian aturan dan ketentuan yang kaku memposisikan guru BK/ konselor pada iklim kerja yang tidak dilandasi sikap profesional namun lebih sekerdar menjalankan kewajiban rutin semata, sehingga guru BK/ konselor kurang memiliki profesionalisme dalam bekerja seperti malas, masa bodoh serta kurang perduli terhadap proses pelayanan BK serta banyak menimbulkan persepsi negatif dari personil sekolah lainnya (Achmad \& Ashariana, 2021; Rosyada, 2017). Dengan hadirnya Manajemen pendidikan yang mengedepankan pendekatan desentralistik-profesional, maka ruang gerak konselor menjadi leluasa. Proses kreatif dan inovatif justru menjadi lebih utama (Mawati, et al., 2020). Konselor didorong untuk memiliki keberanian dan membiasakan diri untuk menemukan cara-cara baru yang lebih efektif dan efisien dalam melaksanakan berbagai kegiatan pelayanan bimbingan dan konseling. Desentralisasi pendidikan sering disebut sebagai otonomi pendidikan atau demokratisasi pendidikan. Desentralisasi pendidikan memberikan kewenangan secara penuh terhadap para pengelola pendidikan termasuk petugas BK untuk merencanakan, melaksanakan, dan menentukan pendidikan dengan kompetensi yang ada secara profesional (Amra, 2016; Kiswantoro, 2014).

Pembelajaran serta pembudayaan merupakan proses yang terintegrasi dalam pendidikan yang ditunjang dengan kualitas pengelolaan pendidikan yang dilakukan oleh pendidikan salah satunya adalah petugas BK yang profesional (Waji, 2015). Guru bimbingan dan konseling atau konselor sebagai pengelola pendidikan dituntut untuk dapat memberikan pelayanan terhadap peserta didik secara profesional untuk meningkatkan kualitas pendidikan (Alaydrus, 2015; Amra, 2016). Upaya yang dapat dilakukan untuk dapat meningkatkan mutu dan kualitas dari layanan BK adalah dengan melakukan pengembangan profesionalisme guru BK agar dapat bekerja secara profesional. Kualitas pendidikan akan terwujud bilamana mampu memberdayakan pengelola pendidikan secara langsung seperti pimpinan sekolah, para guru, dan petugas BK secara profesional. Di samping itu, juga harus memberdayakan pemerintah daerah serta masyarakatnya agar ikut berpartisipasi aktif sesuai kewenangan dan tugasnya masing-masing. Dalam hal ini agar manajemen pelayanan BK disekolah menjadi berkualitas maka guru BK/Konselor harus ditingkatkan keprofesionalannya.Berdasarkan penjelasan diatas tulisan ini bertujuan untuk mendeskripsikan bagaiamana pengembangan profesionalisme guru BK di era disentralisasi pendidikan saat ini yang diberlakukan pada sistem pendidikan di Indonesia.

\section{Metode}

Metode penelitian yang digunakan adalah studi kepustakaan atau literatur review, metode ini memanfaatkan berbagai sumber bacaan atau literatur untuk memperoleh data serta informasi terkait dengan membatasi kegiatan pada bahan-bahan kepustakaan tanpa melakukan riset lapangan dengan mempelajari riset-riset, buku serta artikel-artikel serta sumber bacaan lainnya yang relevan.

\section{Hasil dan Pembahasan}

\section{Manajemen Pendidikan Disentralisasi di Sekolah}

Dalam manajemen pendidikan dikenal dua mekanisme pengaturan, yaitu sistem sentralisasi dan desentralisasi (Setyaningsih, 2017). Dalam sistem sentralisasi, segala sesuatu yang berkenaan dengan penyelenggaraan pendidikan diatur secara ketat oleh pemerintah pusat atau Nasional. Sementara dalam sistem desentralisasi, wewenang pegaturan tersebut diserahkan kepada pemerintah daerah (kabupaten/kota). Tujuan dilakukannya Desentralisasi dalam pendidikan dimaksudkan untuk meningkatkan mutu pendidikan khususnya dari segi manajeman dan pengelolaan atau disebut sebagai istilah Manajemen Berbasis Sekolah/ School Based Management (MBS) (Fattah, 2000; Hamdi, 2011).

Di Indonesia konsep Manajemen Berbasis Sekolah (MBS) ini muncul pertama kali pada tahun 2000. Secara resmi konsep ini tertuang dalam dokumen Undang-undang No. 25 tahun 2000 Rencana Strategis Pembangunan Nasional tahun 2000-2004, selanjutnya tertuang dalam Undang-undang No. 20 Tahun 2003 
tentang Sistem Pendidikan Nasional. Pada Pasal 51 UU Sistem Pendidikan Nasional tercantum bahwa "Pengelolaan satuan pendidikan anak usia dini, pendidikan dasar, dan pendidikan menengah dilaksanakan berdasarkan standar pelayanan minimal dengan prinsip manajemen berbasissekolah /madrasah." Melalui kebijakan tersebut sekolah-sekolah di Indonesia telah menggunakan sistem pendidikan yang disentralisasi dengan menggunakan konsep Manajemen Berbasis Sekolah (MBS). Dalam MBS Kebijakan dan kewenangan sekolah bersumber dari kondisi nyata yang dilingkungan sekolah ataupun masyarakat (Siburian, 2020; Sutarto, Darmansyah, \& Warsono, 2014).

Manajemen Berbasis Sekolah (MBS) merupakan model manajemen yang memberikan otonomi lebih besar kepada sekolah dan mendorong sekolah untuk melakukan pengembalian keputusan secara partisipatif untuk memenuhi kebutuhan mutu sekolah atau untuk mencapai tujuan mutu sekolah dalam kerangka pendidikan nasional. Dalam MBS, konsep yang diterapkan adalah konsep otonomi yang merupakan tindakan desentralisasi yang dilakukan oleh lembaga yang lebih tinggi ke tingkat bawah. Hal ini merupakan proses pendelegasian kekuasaan mulai dari tingkat nasional (pusat) sampai dengan tingkat sekolah, bahkan sampai di tingkat kelas (guru kelas) (Fattah, 2000; Kiswantoro, 2014).

Melalui manajemen berbasis sekolah, kewenangan dalam pengelolaan sekolah, bertumpu kepada sekolah da Jan n stakeholder terkait langsung. Dengan basis ini, fungsi manajemen sekolah lebih terbuka dan optimal, menghindarkan format sentralisasi dan birokratisasi yang dapat menyebabkan hilangnya fungsi manajemen sekolah. Manajemen berbasis sekolah juga didasarkan pada kenyataan bahwa setiap sekolah, layaknya setiap individu, memiliki keunikannya sendiri. Setiap sekolah memiliki karakteristik yang tidak dimiliki sekolah lain. Setiap sekolah memiliki konteks dan kondisi lokal yang berbeda satu dengan yang lain. Oleh karena itu, untuk optimalnya proses pendidikan di tiap sekolah, maka sekolah perlu mengelola sekolah sesuai konteks lokal tersebut (Amra, 2016; Sudarsana, 2018).

\section{Sikap Profesional Guru Bimbingan dan Konseling}

Sumber daya manusia yang berkualitas sangat tergantung dari kualitas pendidikan. Kualitas pendidikan dapat dipersiapkandari dan oleh semua pihak termasuk petugas bimbingan konseling. Untuk itu tampilnya petugas bimbingan konseling sangat menentukan dan berperan dalam menyiapkan SDM yang berkualitas khususnya di daerah. Petugas BK dalam menyiapkan SDM harus dapat menunjukan etos kerja secara professional.Sebagai tenaga professional harus mampu merancang, menganalisis, mengidentifikasi, dan melaksanakan program-program secara benar dan tepat serta dapat menemu-kan jati dirinya sebagai tenaga yang professional (Amra, 2016). Untuk itu para pelaku profesi BK harus dapat menampilkan kepercayaan publik dengan menunjukkan hasil nyata dari karyanya yaitu dengan mencoba merancang, menganalisis, mengidentifikasi, dan melaksanakan program-program yang dapat dirasakan langsung oleh publik secara khusus oleh para personil sekolah. Banyak kalangan yang masih mempertanyakan tentang kadar keprofesionalan para pelaku profesi konseling. Jangankan untuk setting masyarakat, di setting sekolahpun tidak sedikit ditemukan pandangan-pandangan yang merendahkan tugas dan pekerjaan konselor sekolah. Semua itu tentu merupakan sesuatu yang seharusnya disikapi sebagai tantangan dalam upaya menegakkan kemartabatan profesi bimbingan dan konseling (Alaydrus, 2015).

\section{Meningkatkan Mutu Pelayanan serta manajemen BK}

Salah satu isu penting tentang pendidikan saat ini berkenaan dengan penerapan sistem desentralisasi pendidikana dalah penerepan Manajemen Peningkatan Mutu Berbasis Sekolah (MPMBS) yang merupakan proses pengintegrasian, pengkoordinasian dan pemanfaatan dengan melibatkan secara menyeluruh elemenelemen yang ada pada sekolah untuk mencapai tujuan (mutu pendidikan) yang diharapkan secara efisien (Baharuddin, 2017; Prayitno, Wibowo, Marjohan, Mugiharso, \& Ifdil, 2015). Atau dapat diartikan bahwa Manajemen Peningkatan Mutu Berbasis Sekolah (MPMBS) adalah model manajemen yang memberikan otonomi yang lebih besar kepada sekolah dan mendorong pengambilan keputusan yang partisipatif yaitu melibatkan semua warga sekolah berdasarkan kesepakatan bersama (Hamdi, 2011; Patimah, 2015). Dengan adanya otonomi yang lebih besar diharapkan sekolah memiliki kewenangan secara mandiri dalam mengelola sekolah dan memilih strategi dalam meningkatkan mutu pendidikan serta dapat memilih pengembangan program yang lebih sesuai dengan potensi kebutuhan daerah dimana lulusannya akan diproyeksikan. Konsep ini diperkenalkan oleh teori effective school yang lebih memfokuskan diri pada perbaikan proses pendidikan (Modelu \& Pido, 2019; Zola \& Mudjiran, 2020).

Dengan hadirnya Manajemen Peningkatan Mutu Berbasis Sekolah (MPMBS), yang mengedepankan pendekatan desentralistik-profesional, maka ruang gerak konselor menjadi leluasa. Proses kreatif dan inovatif justru menjadi lebih utama (Hamdi, 2011; Pasandaran, 2016). Konselor didorong untuk memiliki keberanian dan membiasakan diri untuk menemukan cara-cara baru yang lebih efektif dan efisien dalam melaksanakan berbagai kegiatan pelayanan bimbingan dan konseling. Dengan kata lain, memasuki alam Manajemen Peningkatan Mutu Berbasis Sekolah (MPMBS), konselor dituntut bekerja secara profesional (Firman, 2019; 
Putri, Neviyarni, Ahmad, \& Syukur, 2018). Penerapan (MPMBS), sebagai upaya meningkatkan kuantitas dan kualitas layanan bimbingan ini konselor hendaknya memperhatikan pengembangan kerja sama, koordinasi dan sinergis kerja dengan berbagai komponen pendidikan lainnya. Karena dalam penerapan Manajemen Peningkatan Mutu Berbasis Sekolah (MPMBS), keberhasilan pendidikan di sekolah tidak lagi didasarkan pada individual yang cerdas, akan tetapi sangat mengutamakan pada team work yang kompak (Bakhtiar, 2019; Pidarta, 2016).

Manajemen pengelolaan Kinerja Konselor pada dasarnya terfokus pada empat pilar kegiatan, yaitu perencanaan (planning-P), pengorganisasian (organizing-O), pelaksanaan (actuating-A), dan pengontrolan (controlling-C) (Kiswantoro, 2014). Pengelolaan berbasis kinerja mendasarkan pelaksanaannya pada kinerja konselor berkenaan dengan POAC penyelenggaraan pelayanan konseling terhadap sasaran pelayanan yang menjadi tanggung jawabnya. Arah POAC adalah : P: Bagaimana konselor membuat perencanaan layanan dan kegiatan pendukung, mulai dari membuat program tahunan,semesteran, bulanan, dan mingguan sampai dengan harian (berupa SATLAN dan SATKUNG). O: Bagaimana konselor mengorganisasikan berbagai unsur dan sarana yang akan dilibatkan di dalam kegiatan. Unsur-unsur ini meliputi unsur-unsur personal (seperti peranan pimpinan sekolah, wali kelas, guru, orang tua), sarana fisik dan lingkungan (seperti ruangan dan mobiler, alat bantu seperti komputer, film, dan objek-objek yang dikunjungi), urusan administrasi, dana, dll. A: Bagaimana konselor mewujudkan dalam praktik jenis-jenis layanan dan kegiatan pendukung melalui SPO masing-masing kegiatan yang telah direncanakan dan diorganisasikan. C:Bagaimana konselor mengontrol praktik pelayanannya dalam bentuk penilaian hasil dan mempertanggungjawabkannya kepada stakeholders. Kegiatan ini melibatkan peran pengawasan dan pembinaan baik dari pihak interen maupun eksteren satuan pendidikan (lembaga kerja), serta organisasi profesi.

\section{Pengembangan Profesionalisme Guru BK/Konselor untuk Meningkatkan Mutu Pelayanan pada Desentralisasi Pendidikan}

Kualitas serta mutu layanan BK ditentukan profesionalitas pelaku BK dalam memberikan pelayanan kepada sasaran layanan, upaya membentuk pelayanan yang profesional diperukan pengembangan sikap profesionalisme pada diri Guru BK (Nirwana, 2013; Rosyada, 2017). Profesionalisme berarti faham atau sikap yang mengutamakan keprofesionalan atau cara kerja sekaligus sikap dan tindak tanduk dari penganutnya. Profesi menjunjung tinggi profesionalisme dalam bekerja, hal ini anggota profesi mementingkan sifat-sifat profesional seperti mementingkan mutu pelayanan, taat kode etik, ingin mengembangkan profesinya, rasa bangga akan profesi, dan meningkatkan kemampuan (Aulia, 2013; Pidarta, 2016).

Konselor seyogyanya tidak merasa cepat berpuas diri dengan kapasitas pengetahuan dan keterampilan yang saat ini dimilikinya, namun justru harus senantiasa berusaha untuk memutakhirkan pengetahuan dan keterampilannya (Nirwana, 2010). Bagaimanapun,dalam era informasi sekarang ini perkembangan ilmu pengetahuan dan teknologi dalam bimbingan konseling dari waktu ke waktu berkembang secara sangat pesat. Sehingga seorang konselor dituntut untuk terus dapat mengantisipasi arah perkembangan yang terjadi, agar tidak menjadi terpuruk secara profesional (As, 2020; Pasandaran, 2016). Upaya peningkatan kapasitas pengetahuan dapat dilakukan dengan berbagai cara, baik secara langsung maupun tidak langsung. Secara tidak langsung, bisa saja dilakukan melalui berbagai bacaan atau buku yang berhubungan dengan dunia bimbingan dan konseling, atau bahkan bila perlu dilakukan dengan cara melalui penjelajahan situs-situs dalam internet, yang memang banyak menyediakan berbagai info rmasi terkini, termasuk yang berhubungan dengan bimbingan dan konseling (Alisjahbana, 2000; Sudarsana, 2018).

Sedangkan secara langsung, bisa dilakukan dengan cara melibatkan diri dalam berbagai aktivitas forum keilmuan, seperti : seminar, penataran dan pelatihan, atau mengikuti kegiatan MGP seperti sekarang ini. Bahkan, akan lebih baik jika timbul kemauan untuk berusaha menuntut ilmu melalui jenjang pendidikan formal (Rosa, Marjohan, \& Said, 2016; Rosyada, 2017).Sedangkan untuk meningkatkan keterampilan berbagai teknik bimbingan, salah satu cara yang dipandang cukup efektif adalah dengan berusaha secara terus menerus dan seringkali mempraktekkan berbagai teknik yang ada. Misalkan, untuk menguasai teknik-teknik konseling, tentunya konselor harus mempraktekkan sendiri secara langsung, dan setiap setelah selesai mempraktekkan, diikuti dengan evaluasi terhadap apa yang telah dilakukan. Kemudian, membandingkannya dengan keharusan-keharusan berdasarkan teori yang ada, sehingga akan bisa diketahui kelemahan dan keunggulan dari praktek yang telah dilakukan. Memasuki tahap praktek konseling berikutnya tentunya sudah disertai usaha perbaikan, dengan bercermin dari kekurangan- kekurangan pada praktek konseling sebelumnya (Nirwana, 2016; Widianto \& Purwandari, 2020).

Konselor dituntut untuk lebih meningkatkan mutu kinerja dan tingkat produktivitas dalam memberikan layanan bantuan terhadap para siswa. Jika hal ini tidak terpenuhi maka konselor harus bersiap-siap untuk menerima berbagai complain dari masyarakat yang mungkin tidak mengenakkan. Upaya meningkatkan kuantitas dan kualitas layanan bimbingan ini konselor hendaknya memperhatikan pengembangan kerja sama, 
koordinasi dan sinergis kerja dengan berbagai komponen pendidikan lainnya (Alaydrus, 2015; Neviyarni, Andriani, \& Ahmad, 2018).

\section{Simpulan}

Sistem manajemen pendidikan di Indonesia mengalami perubahan dari sentralisitik menjadi desentralisitik yang dianggap menjadi pendekatan pendidikan dengan mengedepankan demokrasi dan kemandirian pendidikan. Desentralisasi pendidikan memberikan kewenangan secara penuh terhadap para pengelola pendidikan termasuk petugas BK untuk merencanakan, melaksanakan, dan menentukan pendidikan dengan kompetensi yang ada secara profesional. Untuk mewujudkan semua itu harus dapat memberdayakan layanan bimbingan konseling terhadap semua pihak dan stakeholder dengan menggunakan berbagai prinsip, azas, dan fungsi bimbingan secara professional dan optimal. Kemudian guru BK dituntu untuk dapat selalu mengembangkan profesionalisme melalui pengembangan diri, keterampilan, IPTEK, serta koordinasi dengan personil sekolah serta masyarakat secara umum untuk dapat memberikan pelayanan BK secara lebih optimal dan berkualitas.

\section{Referensi}

Achmad, M., \& Ashariana, A. (2021). The Energy Dynamics Of Decentralization From 2004 To 2020. Al Qodiri: Jurnal Pendidikan, Sosial dan Keagamaan, 18(3), 790-803.

Alaydrus, A. K. (2015). Pengembangan Profesionalisme Guru di Era Desentralisasi Pendidikan. Palapa, 3(2), 163-180.

Alisjahbana, A. S. (2000). Otonomi daerah dan desentralisasi pendidikan. Bandung: FE Universitas Padjadjaran.

Amelia, D., Firman, F., \& Rusdinal, R. (2019). Pendidikan dalam Pemikiran Mohammad Hatta. Jurnal Pendidikan Tambusai, 3(3), 1506-1513.

Amra, A. (2016). Profesionalisme Guru untuk Meningkatkan Mutu Pendidikan di Era Teknologi Informasi. Ta'dib, 14(2).

As, U. M. (2020). Pengembangan Profesi Bagi Guru Madrasah Aliyah Melalui Diklat PKG Dan PKB Di BKD Jakarta. Wawasan, 1(1), 30-37.

Aulia, S. (2013). Desentralisasi Kebijakan pendidikan (studi tentang pelaksanaan wajib belajar 12 tahun di kota surabaya pada tingkat pendidikan menengah dan kejuruan). Jurnal Politik Muda, 2(1).

Baharuddin, B. (2017). Manajemen Peningkatan Mutu Berbasis Sekolah (MPMBS). Idaarah: Jurnal Manajemen Pendidikan, 1(1).Bakhtiar, B. (2019).

Manajemen Peningkatan Mutu Berbasis Sekolah (MPMBS). At-Ta'lim: Media Informasi Pendidikan Islam, 12(2), 176-185.

Fattah, N. (2000). Manajemen Berbasis Sekolah (School Based Management). Bandung, Indonesia: Andira.

Firman, F. (2019). Strategi Dan Pendekatan Pelaksanaan Bimbingan Konseling Di Sekolah Untuk Menghadapi Revolusi Industri 4.0.

Gaol, N. T. L. (2020). Sejarah dan konsep manajemen pendidikan. Jurnal Dinamika Pendidikan, 13(1), 79-88.

Hamdi, M. M. (2011). Implementasi program Manajemen Peningkatan Mutu Berbasis Sekolah. Jurnal Administrasi Publik (Public Administration Journal), 1(2), 130-159.

Kiswantoro, A. (2014). Manajemen Peningkatan Mutu Berbasis Sekolah untuk Peningkatkan Profesionalisme Guru Bimbingan dan Konseling/Konselor. Refleksi Edukatika: Jurnal Ilmiah Kependidikan, 4(2).

Kuswandi, A. (2011). Desentralisasi pendidikan dalam penyelenggaraan otonomi daerah di Indonesia. governance, 2(1), 69-98.

Mawati, A. T., Permadi, Y. A., Rasinus, R., Simarmata, J., Chamidah, D., Saputro, A. N. C., et al. (2020). Inovasi Pendidikan: Konsep, Proses dan Strategi: Yayasan Kita Menulis.

Modelu, R., \& Pido, A. (2019). Manajemen Peningkatan Mutu Berbasis Sekolah (MPMBS): antara Harapan dan Realita di SMA Negeri 3 Atinggola. Al-Minhaj: Jurnal Pendidikan Islam, 2(1), 128-142.

Neviyarni, N., Andriani, I., \& Ahmad, R. (2018). Academic stress level guidance and counseling students at Universitas Negeri Padang. Konselor, 7(2), 55-62.

Nirwana, H. (2010). Layanan Konseling dan Mutu Pendidikan. Repository UNP.

Nirwana, H. (2013). Peningkatan Keprofesionalan Konselor Sekolah di Lapangan. Repository UNP.

Nirwana, H. (2016). Hubungan Persepsi Klien tentang Konseling dan Ketrampilan Komunikasi Konselor dalam Konseling dengan Pengungkapan Diri Klien. Jurnal Ilmu Pendidikan, 5(1).

Pasandaran, S. (2016). Desentralisasi Pendidikan dan Masalah Pemberdayaan Sekolah. Jurnal Ilmu Pendidikan, 11(2). 
Patimah, S. (2015). Manajemen kolaboratif guru bidang studi dan guru bimbingan konseling dalam rangka meningkatkan mutu pendidikan siswa pada SMA Muhammadiyah Kasongan. IAIN Palangka Raya.

Pidarta, M. (2016). Desentralisasi Pendidikan di Tingkat Kabupaten. Jurnal Ilmu Pendidikan, 8(1).

Prayitno, P., Wibowo, M., Marjohan, M., Mugiharso, H., \& Ifdil, I. (2015). Pembelajaran melalui Pelayanan BK di Satuan Pendidikan: Pengembangan Manusia Seutuhnya. Yogyakarta: Paramitra Publishing.

Putri, M. A., Neviyarni, N., Ahmad, R., \& Syukur, Y. (2018). Guidance and Counseling in School Accountability. ENLIGHTEN: Jurnal Bimbingan Konseling Islam, 1(2), 108-117.

Rahmadi, G. A. (2020). Pengaruh Desentralisasi Fiskal Terhadap Kesejahteraan Masyarakat Indonesia Di Bidang Pendidikan. Jurnal Ilmiah Mahasiswa FEB, 8(2).

Rosa, S. S., Marjohan, M., \& Said, A. (2016). Persepsi Siswa tentang Kompetensi Profesional Guru Bimbingan dan Konseling. Konselor, 3(1), 7-11.

Rosyada, D. (2017). Madrasah dan Profesionalisme Guru dalam Arus Dinamika Pendidikan Islam di Era Otonomi Daerah: Kencana.

Setyaningsih, K. (2017). Esensi Tranformasi Sistem Sentralisasi-Desentralisasi Pendidikan Dalam Pembangunan Masyarakat. El-Idare: Jurnal Manajemen Pendidikan Islam, 3(1), 76-94.

Siburian, M. E. (2020). Fiscal Decentralization, Regional Income Inequality, and the Provision of Local Public Goods: Evidence from Indonesia.

Sudarsana, I. K. (2018). Peran Keluarga Dan Masyarakat Dalam Desentralisasi Pendidikan Nasional. Maha Widya Bhuwana: Jurnal Pendidikan, Agama dan Budaya, 1(1).

Sutarto, M., Darmansyah, D., \& Warsono, S. (2014). Manajemen berbasis sekolah. The Manager Review Jurnal Ilmiah Manajemen, 13(3), 343-355.

Waji. (2015). Penerapan Bimbingan Konseling Dalam Kurikulum 2013 Melalui Otonomi Pendidikan Pada Pelaksanaan Otonomi Daerah. Pena Jurnal Ilmu Pengetahuan dan Teknologi, 29(1).

Widianto, W. W., \& Purwandari, S. (2020). Workshop Optimalisasi Teknologi Informasi Guna Mendukung Kinerja Guru BK Serta Peningkatan Pelayanan Konseling Kepada Siswa SMA SMK. Jurnal Sainstech, 7(1), $69-76$.

Yuhasnil, Y. (2020). Manajemen Kurikulum dalam Upaya Peningkatan Mutu Pendidikan. Alignment: Journal of Administration and Educational Management, 3(2), 214-221.

Zola, N., \& Mudjiran, M. (2020). Analisis urgensi kompetensi kepribadian guru. Jurnal EDUCATIO: Jurnal Pendidikan Indonesia, 6(2). 